\title{
Space traffic management - key issue for Industry 4.0
}

\author{
Ulpia Elena Botezatu ${ }^{1,2 *}$ and Olga Bucovetchi ${ }^{2}$ \\ ${ }^{1}$ Romanian Space Agency, 21-25, Mendeleev St., Bucharest, Romania \\ ${ }^{2}$ University Politehnica of Bucharest, Economic Engineering Department, 313. Spl Independentei, \\ Bucharest, Romania
}

\begin{abstract}
Space technology and services represent a major component of the well-functioning societies' infrastructure. At the same time, outer space is being increasingly accessed with many entities sending out technologies in an attempt to minimize launching and operational costs. Subsequently, a cross-domains activity, space technologies and services lay in the insufficiently settled area of legislative and institutional measures, leading to a growing ambiguity among professional community, reunited under the concept of "space traffic management" (STM). In line with the new initiatives in the field of STM, this paper attempts to unblackbox the interplay between definitions and establishment history of it, its context of emergence, usage and the level of technological maturation. At the same time, the paper intends to address the tension between governmental and private initiatives related to the management and the coordination for space traffic, in order to open up a discussion on this topic. Thus the paper is expected to contribute to building a better understanding of the controversial nature of space services and technologies, especially with regard to delineations among geopolitical groups of interest, economic and governmental uses, as well as interfacing, roles and responsibilities, and impact on interoperable means of communication among various institutions.
\end{abstract}

\section{On the importance of Space Traffic Management}

Space has become interwoven into the global humanity. Obstacles to accessing space have felt down and numerous nation-states now have their own space programs. Currently, more than 80 countries own or operate satellites, and space services became so ubiquitous that every person on the planet uses space data/services in a form or another. This situation allows for the benefits of space to extend past the well-known space players towards including nation-states worldwide as well as private players that are increasingly present in space.

This current situation highlights the tensions between humanity's activities in the past and in the future. On the one side, past space activities put at risk both the safety and sustainability of space traffic. On the other side, countries and other space actors rely on

*Corresponding author: ulpia.botezatu@,rosa.ro, olga.bucovetchi@upb.ro 
space activities as drivers of economic growth. Nevertheless, recently actors in Europe and the United States have opened up towards building a reliable Space Traffic Management (STM) framework. This has been done by policy documents, position papers, and generally with opening up the public debate surrounding this topic.

The safety and sustainability of space traffic is jeopardized by the increased number of space debris and the expansion of space traffic. Space debris represents remains from previous space missions as well as whole satellites that are no longer operational. Currently there are around 128 million pieces of debris smaller than $1 \mathrm{~cm}$, approximately 900000 pieces of debris from one to ten $\mathrm{cm}$, and 34000 pieces larger than $10 \mathrm{~cm}$, that all orbit Earth. These pieces of debris cannot be controlled or manoeuvred, it travel in different orbital altitudes at speeds of up to 28,000 kilometres per hour and can impact more than 2,200 active satellites in LEO (Low-Earth orbit) only, or other pieces of debris creating eve more pieces of space junk. Collisions between space junk and satellites are a major concern in the space community, especially in Low Earth Orbit, this being the most impacted and the most congested orbit. Not only due to increased debris, but also because of the expansion of the space traffic. The development of several mega-constellations, of private capacities for space launch and the decreasing costs to launching spacecraft contribute to space becoming more congested. In the coming years it is estimated that more than 20000 additional satellites will be launched worldwide.

In terms of associated costs to STM, operators only move a satellite if the probability of space debris collision is high. Furthermore, these moves to avoid a collision costs fuel, time and effort and are to be avoided.

In conclusion, the tendency globally is to enforce space traffic management and various initiatives exist at global, regional and national level.

\section{Space Traffic Management recently}

On September 22, 2020, U.S. Space Command informed the International Space Station that an unidentified piece of debris would come within 1.4 kilometres of it, later found to be debris from an H-2A rocket upper stage that broke apart last year [1]. Luckily, this event ended up with no damages, but this is precisely that kind of situation that requires a coordinated approach to the space traffic. Even more recent, a similar event involved a collision avoidance manoeuvre for satellite GSAT0219 following a collision risk alert received from EU Space Surveillance and Tracking (EUSST) [2].

Currently, probable space collisions are attempted to be predicted ahead of time. However, due to the high uncertainty when determining if a collision will actually occur, up to the point that incertitude lasts until few minutes before of the possible impact. As a result, we currently experience a lot of effervescence around the topic of Space Traffic Management at national, regional and global levels.

Space Traffic Management reads as the 'planning, coordination and on-orbit synchronization of activities to enhance the safety, stability, and sustainability of operations in the space environment'[3]. Nevertheless, this is a working definition adopted by the United States, while Europe still struggles with finding its own approach and terminology. Our aim here is not getting into this lexical debate because there are so many better references on that in the literature - see inter alia [10]. Instead, we choose to briefly review the literature on the subject and to focus on what space traffic management would mean for industry. Space Traffic Management (STM) is used for regulation of space activities within the United Nations Committee on the Peaceful Uses of outer Space (UNCOPUOS), as well as in other fora $[6,10]$. Despite if its apparent novelty, the concept of Space Traffic Management (STM) has been first referenced in 1932 in Czechoslovakia by Vladimir Mandl, a jurist that wrote the first monograph on space law [10]. Later on, a 2006 IAA 
Cosmic Study on Space Traffic Management [5, 9] defined STM as a possible comprehensive approach necessary to secure sustainable development of future space activities, a "set of technical and regulatory provisions for promoting safe access into outer space, operations in outer space and return from outer space to Earth free from physical or radio-frequency interference." Other authors see STM as interdisciplinary activities situated at "the intersection of the technical, and space law and policy; industry, government, and education", characterizing STM as a "process" [11]. While nation-states contemplate the coming into force of clear rules to regulate the coordination of space traffic, in space there is an unprecedented activity. Major spacefaring nations are pushing towards establishment of national STM regimes that would hopefully evolve into an international regime in the near future [12]. In the United States, the US SPD-3 Directive defines STM as "the planning, coordination, and on-orbit synchronization of activities to enhance the safety, stability, and sustainability of operations in the space environment." [3]

Currently we are fast approaching a new space travel revolution, as programs such as NASA's Artemis and ESA's new astronaut selection are coming to live. But this time it shall not be only about one or two agencies sending humans into space, since commercial actors (SpaceX, Virgin Galactic, etc.) plan to do the same, even to "democratize" space travel. Another important difference comes from plans to develop several space stations orbiting the Earth in parallel or after the International Space Stations (ISS) will be decommissioned. In such a context it can be foreseen that with the advent of a more complex inclusion of the human factor into the equation, the importance of STM will increase several folds, becoming somewhat equivalent to the existing Air Traffic Management (ATM).

The international community just recently started working on finding a common denominator among various definitions. It is not in the scope of this paper to compare and contrast these more or less mature linguistic and conceptual initiatives; nor to enter debates about our interpretation of these definitions. We acknowledge the previous work undertaken by other scholars and institutions [8, 13, 14].

A space policy and a national administrative system to manage STM represent essential aspects of a nation's space governance. A national space policy defines the roles and responsibilities of different players and stakeholders. It also highlights the different components that of the national space constellation, including, inter alia, investment made by the private sector, various interests of non-governmental entities and civil society, the foundational role that science and technology is playing in the space technology, as well as national and regional enforcement of controls on exports and imports. At the same time, it highlights a country's international obligations, disputes and liabilities of the international regime. Establishing an STM national regime is therefore a complex task comprising a wide range of a nation's undertakings in the complex management of the space sector.

Some of the Space Situational Awareness' (SSA) systems were initially built for military use only but slowly dualized their use by adding a civilian component. A symbolic example for this dualism is represented by the U.S. SSA systems. The largest share of data is collected by the United States Space Command (USSPACECOM) using its Space Surveillance Network (SSN). This network of electro-optical and radar sensors detects, monitors and identifies Earth orbiting objects, which are then added to a space objects catalogue and published in different formats. On the other hand, Japan has implemented the reverse process, its SSA systems, initially designed for civilian use, soon became useful in military operations [15].

Nowadays Russia operates the second most important of the SSA radars, after the US. The Russian Space Surveillance Systems, uses various electro-optical sensors and ground-based radars in and outside its borders, and controls a satellite database analogous to the US one. The Russian Federation signed bilateral arrangements with the host countries to continue 
using these facilities. [16, 17]. Roscosmos, the Russian Space Agency is the direct responsible for the security of Russian space operations. The Ministry of Defence is engaged in all the Russian military operations in outer space and in their surveillance and support. At the same time, organizations such as The Russian Academy of Sciences, The Foreign Ministry and others are cooperating in the development of SSA planning, data sharing and international cooperation operations [18].

In Europe, relevant dual use contribution in the field of Space Surveillance and Tracking (SST) was made by France (GRAVES radar) and Germany (TIRA radar) respectively [19]. As the European interest in SST grew, the EU created in 2014 The Space Surveillance and Tracking Support Framework, with Decision 541/2014 / EU of the European Parliament and the Council, a Consortium originally formed from France, Germany, Italy, Spain and UK, joined by Poland, Portugal and Romania in 2018 [20]. SST refers to the capacity to detect, catalogue and predict the movements of space objects orbiting the Earth. European institutions expressed that services will not aim at serving purely military goals [21], as they are intended to be civil in nature and for dual use purposes.

The Space Surveillance and Tracking Support Framework (EUSST) provides three types of services that help monitor the outer space events regarding artificial objects, and set up added value to STM: analysis of space objects fragmentation, prediction and evaluation of collision risks (collision avoidance) and re-entry analysis of space debris in Earth's atmosphere [4]. Another objective of the EUSST program is to ensure the appropriate level of European autonomy by exploiting existing national assets, together with the development of a European SST capacity [22]. The Consortium relies on a unique model of governance suitable for a fruitful European multilateral space cooperation. Fully recognizing the likely sensitive civilian-military dimension of SSA authority and related aspects of national sovereignty, all the activities of the Consortium are undertaken without interfering with bilateral agreements or national security protocols. Furthermore, this model grants the participating nations of the EUSST Consortium ownership and full control on their national sensors. In order to ease this, military and civilian nominees from MoDs and space agencies, collaborate at various levels of the domestic administration.

\section{Industry and Space Traffic Management: Space 4.0}

The global space economy has grown to an estimated value of more than \$420B in 2019 and it could surge to over $\$ 1$ trillion by 2040 [23]. Largely driven by American actors, commercialization of space activities currently registers a worldwide expansion. This expansion has never been experienced before and hence it brings forth new actors, new application areas and new business models [24]. For instance, approximately $68 \%$ of the total investment in 2019 was being made by three companies: SpaceX, OneWeb and Virgin Galactic. Another recent report from the Satellite Industry Association (SIA) compiled an estimation of satellites to been proposed or operating for providing commercial services by 2029 [25] (see table 1).

Table 1. Commercial satellites operating or proposed for launching by 2029.

\begin{tabular}{|c|c|}
\hline Total satellites estimated by 2029 & Number of satellites \\
\hline LEO & 10.000 \\
\hline MEO & 30.000 \\
\hline GEO & 107.671 \\
\hline
\end{tabular}


It is necessary here to mention the concept of "New Space" that is "defined as "private companies, which act independent of governmental space policies and funding, target equity funding and promote affordable access to space and novel space applications" [26]. Many entrepreneurs reduce their investment costs by benefitting from the systems developed by government funding in terms of satellites and launchers. They can, therefore, propose more affordable applications in specific markets, which are not the prime targets of the commercial space companies focusing on large turnovers. New Space activities include large LEO constellations as well as small satellites such as CubeSats. Some of these new operators however, 'are employing novel methods of satellite design, construction and operation that could lower the satellite reliability and increase the possibility of failures' [27].

The term "Industry 4.0" promotes the computerization of manufacturing, i.e. the ongoing automation of traditional manufacturing and industrial practices, using modern smart technology. These reshaping and the strong customization of products is based in few design principles such as: interconnection (the ability of machines, devices, sensors, and people to connect and communicate via the Internet of things), information transparency, technical assistance (the technological facility of systems to assist humans in decisionmaking and problem-solving), as well as the decentralisation of decisions, i.e. he ability of cyber physical systems to make decisions on their own and to perform their tasks as autonomously as possible.

In the space domain, as the European Space Agency (ESA) calls it, the Space 4.0 represents 'a time when space is evolving from being the preserve of the governments of a few spacefaring nations to a situation in which there is the increased number of diverse space actors around the world, including the emergence of private companies, participation with academia, industry and citizens, digitalisation and global interaction' (European Space Agency). This perfectly aligns to the ideas of 'New Space' presented above. Further on, the concept of Space 4.0 is being built upon previous ideas of Space 1.0 - the early study of astronomy, Space 2.0 - the beginnings of space race, and finally Space 3.0 - ISS as the headline for space cooperation.

Historically though, the commercial actors were little involved in governmental provision of space services, especially in the area of satellite telecommunication services, some limited remote sensing activities and a limited amount of commercial space launch services, of course with many other private entities depending on governmental programs. However, recently this private sector is booming due to easy access to capital, and the spread of a disruptive innovation spirit.

While at the international level, the major space-faring nations might be tempted to resolve the challenge of STM by adopting national legislation, this is a process more complicated than it seems. Moreover, while discussions on the topic are not mature enough to take action upon them, the issue of STM is too critical not to act. Nevertheless, developing individual national legislation would rather foster a silo approach that tends to miss some of the cooperative approaches so much needed for regulating STM.

One example refers to the recent activities of the American National Standards Institute (ANSI) that released a report in December 2020 on the "Standardization and the Commercial Space Industry - Space Situational Awareness, Space Traffic Coordination and Management, and Orbital Debris Mitigation" [28]. One panel explored the American industry needs for standards and emphasized especially the public private partnerships through which the public sector could benefit from the agility and the reactive potential of the private sector.

It is therefore important to note that neither industry, nor the governments, cannot work in isolation from one another. While each of these segments has its own flaws, they also provide the means and the expertise to cooperate for a safer space traffic management. 
As congestion increases specially on LEO, the prediction of potential collisions is critical. Nevertheless, predicting these events requires 'adequate data, advanced algorithms, identification, and tracking techniques' [29]. And this example highlights the importance of cooperation between the public and the private sectors. Romania, through the Romanian Space Agency (ROSA) participates to all industrial and policy-related initiatives and programmes related to the development of space industry as well as to regulating space traffic. Nevertheless, albeit these activities are increasing, currently national contributions are rather linked to Romania's membership to the ESA and to the European Union Space Surveillance and Tracking Consortium (EUSST). In fact, the so called 'space 4.0'could bring many benefits to the national space entities, especially in the downstream segment, in addition to space manufacturing industry, and therefore would likely deliver further economic benefits to the space industry. Among these are those technologies that could enable potential market opportunities, such as the popular large constellations, as well as the benefits for non-terrestrial space activities, such as in orbit manufacturing.

Since 1957, in Romania, scientific research activities have been carried out in the fields of space weather, astrophysics and some specific services, such as terrestrial geomagnetic field monitoring, processing of SSA observational data for third parties and consulting. Nowadays, the fruitful collaboration between experts from academia, industry and at decisional level led to the development of a national SSA program with activity in all its segments: space surveillance and tracking, near-Earth objects (NEO) and space weather (SWE) monitoring. The sensor network was developed during recent years; equipped with latest technology in data acquisition that allows the monitoring of outer space threats coming from different size objects from the solar system, ranging from large to small, from artificial space objects orbiting the Earth and from those originated by solar activity. Based on data received from all sensors, on national level several programs of space situational awareness were established; this includes a platform where a group of Romanian entities that activate in the space domain gather all the data and provide different specific products and services such databases, maps, space weather forecast, orbit prediction, scientific content and links to other similar platforms and data repositories so that a potential user can have a wide image about the SSA concept and can obtain all the required information.

The current national research strategy includes, within the main directions of action, the support of intelligent specialization on four directions, one of them being the issue of space and security. In recent years, within the National Research and Development Program, the STAR Program and through European funded projects, a potential in the field of space surveillance has begun to emerge.

The national SSA system attempts to systematize coherently the research, monitoring and forecasting of the situation in outer space in the field of SSA. Thus, the national SSA System aims at having permanent knowledge of the critical space infrastructure of Romania; at assessing possible threats from space and at ensuring the public or specific information measures necessary for the achievement of a stable socio-economic environment, in consensus with the needs of sustainable development of Romania; as well as to provide a supportive information environment for military activities.

The national architecture included in the EUSST network currently consists of sensors located in different areas of the country, i.e. six telescopes; also, plans are in place in order to include in the near future a radar as well. Each sensor, individually or in other configurations, is also part of many other projects and activities related to SSA and its 
segments. In medium-term, these national assets will be providing useful information for the STM.

\section{Conclusions and discussions}

In recent years, space activities have gathered much broader public attention due to the massive changes and advances that are happening. Among these changes are the commercialization of outer space activities at the same time with an increased congestion of the main orbital regimes. This situation in outer space needs careful consideration at the same time with a coordinated approach at global level. However, while some intergovernmental entities have started a dialogue on the topic of managing the space traffic, there is much work left to actually achieve consensus. Furthermore, the industrial players are not always taken on board into governmental decisions and this is definitely an area that needs more responsiveness.

Having said that, this article attempted to highlight the importance of tackling the management or coordination of space traffic, especially in relation to space industry or industrial actors. This situation is even more central because even though there can be parallels with the air or maritime domains, the physics of how objects move in space, i.e. the orbital mechanics, present unique challenges.

The growth in commercial space activities has stretched the current rather military or governmental-led space activities to a point where some sort of a new framework of thinking is needed. Therefore, when discussing the subject of managing the space traffic it is important to highlight that establishment of an international dialogue on regulating commercial space is critical. Moreover, this is in addition to rethinking the current model for providing space data and services to reflect more the reality of these times as opposed to models set in place during the space race some decades ago.

Space traffic is evolving, both in its constituency and in the activities represented by new space operations. Standards in STM must evolve to keep up with the changing environment at the same time with governmental institutions widening up their influence to include a broader network of institutions involved into reducing orbital debris and support the long-term sustainable uses of space.

Coordination, no matter how obsolete it sounds, still remains the fundamental tool in managing this emerging aspect. Outreach and transparency between industry, stakeholders and governmental entities is key, as well as the development of a structured relationship with the private sector. Also setting up a dialogue with international partners and seeking communication and collaboration on a global level. In any of the SST/STM activities, integration and assurance of commercial services would be critical.

For continuing peaceful activities in outer space in a sustainable manner, stakeholders worldwide need to take into account ways (strategic, operational, legal, institutional, and others) to ensure that all players preserve a safe, secure and sustainable space environment. Thus, partnerships are a crucial element in developing such a collaborative approach. Developing only military assets and processing functions is not a feasible way to manage sensitive information, and for this reason, a more straightforward solution is to include civilian assets into this system. This method implies the need to establish, in case-by-case situation, data-sharing agreements regarding the security of information.

Romania's plans to develop the SST capabilities are aligned with international and European objectives, many of them being already ongoing. Establishing a SST network implies the collaboration between entities from different domains, as academia, public institutions, private sector or industry, but the experience showed that it is possible, with promising results. 


\section{References}

1. Foust, J. Space traffic management idling in first gear. November 3, 2020. [Online] Available: https://spacenews.com/space-traffic-management-idling-in-first-gear/

2. GSA. Galileo satellite performs collision avoidance manoeuvre. March 10, 2020. [Online] Available: https://www.euspa.europa.eu/newsroom/news/galileo-satelliteperforms-collision-avoidance-manoeuvre

3. White House. "Space Policy Directive-3, National Space Traffic Management Policy." June 18, 2018. [Online]. Available: https://trumpwhitehouse.archives.gov/presidentialactions/space-policy-directive-3-national-space-traffic-management-policy/. [Accessed 25 April 2021]

4. C. Bonnal, et al. Acta Astronaut. 167, 296-301 (2020).

5. C. Contant-Jorgenson, P. Lala, and K. - U. Schrogl. Space Policy 22, 283 - 288 (2006).

6. N., C. Antoni, Giannopapa, and K.-U. Schrogl. Space Policy 53, 1-9 (2020)

7. ESPI. Towards a European Approach to SpaceTraffic Management. ESPI, 2020.

8. M.P. Gleason, J Space Saf Eng, 7 (3) 426-431 (2020).

9. K. - U.Schrogl, Acta Astronautica 62, 272-276 (2008).

10. Q. Verspieren, Opening Keynote (Day 2), 21 st Advanced Maui Optical and Space Surveillance Technologies, AMOS Conference, Maui, Hawai, (2020)

11. M.A.,Skinner, M.K. Jah, D. McKnight, D. Howard, and D. Murakami. J Space Saf Eng 6, 88-91 (2019)

12. Secure World Foundation, (SWF). Handbook for new actors in space. (Denver, Colorado: Integrity Print Group, 2017)

13. K.U., Schrogl, C. Jorgenson, J. Robinson, and A. Soucek. Space Policy 22, 4, 283-288 (2006).

14. Oltrogge, D. "Hearing of the Committee on Science, Space, and Technology, U.S. House of Representatives, "Space Situational Awareness: Key Issues in an Evolving Landscape"." February 11, 2020.

15. Y., Otani, and N. Kohtake. Space Policy 47, 140-147 (2018).

16. P. Podvig, H. Zhang, Russian and Chinese Responses to U.S. Military Plans in Space, (American Academy of Arts and Sciences, Cambridge, 2008)

17. P. Podvig, Sci. Glob. Secur 14, 75-115 (2006).

18. Russian Space Surveillance System (RSSS). [Online]. Available: https://www.globalsecurity.org/space/world/russia/space-surveillance.htm. [Accessed 25 April 2021]

19. J. Ayadi, Military implications of the use of outer space: a European perspective, $42^{\text {nd }}$ Round Table on Current Issues of International Humanitarian Law on the $70^{\text {th }}$ Anniversary of the Geneva Conventions "Whither the human in armed conflict? IHL implications of new technology in warfare". San Remo: International Institute of Humanitarian Law, (2019)

20. EUSST. What is EU SST? [Online]. Available: https://www.eusst.eu/. [Accessed 25 April 2021]

21. European Parliament and the Council decision $N^{\circ} 541 / 2014 / E U$ establishing a Framework for Space Surveillance and Tracking Support. (2014)

22. P., Faucher, R. Peldszus, and A. Gravier, J Space Saf Eng 7, 420-425, (2020).

23. Morgan Stanley. The Space Economy's Next Giant Leap. 2021. [Online]. Available: https://www.morganstanley.com/Themes/global-space-economy. [Accessed 25 April 2021]

24. Secure World Foundation. Space Policy and Sustainability: Issue briefing for Biden administration. Washington, D.C.: Secure World Foundation, (2020) 
25. Association, Satellite Industry. "SIA White Paper: The Future of Space and Space Traffic Coordination and Management." September 23, 2020. [Online]. Available: https://sia.org/wp-content/uploads/2020/09/REVISED-White-Paper20-STCM-Sept23rd-V1.0.pdf. [Accessed 25 April 2021]

26. W. Peeters, New Space 6, 3, 187-190 (2018).

27. Aerospace Corporation, Center for Space Policy and Strategy. Space Traffic Management in the age of New Space. Aerospace Corporation, (2018)

28. American National Standards Institute. Standardization and the Commercial Space Industry - Space Situational Awareness, Space Traffic Coordination and Management, and Orbital Debris Mitigation. Meeting Report, New York: ANSI, (2020)

29. Space Traffic Management (STM): Balancing Safety, Innovation, and Growth. Position paper, American Institute of Aeronautics and Astronautics, (2017) 